\title{
В.М. ГРИЩЕНКО
}

\section{СХЕМА АЛГОРИТМУ ПОКРОКОВОГО ПРИВЕДЕННЯ ДВОХ МАТРИЦЬ У ФОРМІ ШУРА ДО ПРОСТОГО ВИДУ}

Важливого значення для сучасної техніки набувають питання динамічної поведінки машин та конструкцій. Зважаючи на тенденції сьогодення такі як нові інформаційні технології, трансформація проектно-конструкторських процесів; створення систем САПР (систем автоматизації проектних робіт), особливого значення набувають питання удосконалення методів рішення задач динаміки. Чисельне моделювання стало невід'ємною частиною дослідження самих складних процесів для самих складних фізичних моделей, a Finite Element Method став основним чисельним методом їх дослідження. Зазначені тенденції невідворотно будуть супроводжуватись значним ростом кількості параметрів визначення стану об'єктів. Зокрема, в динаміці машин значної кількості степенів вільності. Як наслідок, появу проблеми багатократного збільшення розмірів задачі.

Рішення проблеми власних значень (EigenValue) може розглядатись як важлива компонента в побудові чисельноаналітичних підходів, які альтернативні простим покроковим схемам інтегрування типу Рунге-Кутта в задачах великого розміру. Можна одержати певні переваги, якщо матриці лінійних перетворень попередньо привести до простих форм. Такий підхід широко застосовується в динаміці (модальний аналіз). В даній роботі запропонована схема алгоритму покрокового чисельного аналізу структури матриці $K$ в проблемі $(K, E) \rightarrow(J, E)$ та схема побудови жорданового базису для загального випадку коренів характеристичного поліному (для дійсних та комплексних коренів, простих та кратних). В якості стартової форми прийнята стандартна проблема власних значень 3 матрицею К попередньо приведеною до форми Шура (матрицею блочно-трикутної форми) . Схема супроводжується рішенням модельних прикладів.

Ключові слова: проблема власних значень, канонічна форма, жордановий базис, чисельний алгоритм.

\section{В.Н. ГРИЩЕНКО}

\section{СХЕМА АЛГОРИТМА ПОШАГОВОГО ПРИВЕДЕНИЯ ДВУХ МАТРИЦ В ФОРМЕ ШУРА К ПРО- СТОМУ ВИДУ}

Важное значение для современной техники приобретают вопросы динамического поведения машин и конструкций. Учитывая тенденции сегодняшнего дня такие как новые информационные технологии, трансформация проектно-конструкторских процессов; создание систем САПР (систем автоматизации проектных работ ), особое значение приобретают вопросы усовершенствования методов решения задач динамики. Численное моделирования стало неотъемлемой частью исследований самых сложных процессов для самых сложных физических моделей, a Finite Element Method стал основным численным методом их исследования. Указанные тенденции неотвратимо будут сопровождаться значительным ростом количества параметров состояния объекта. В частности, в динамике машин значительное число степеней свободы. Как следствие, появление проблемы многократного увеличения размеров задачи.

Решение проблемы собственных значений (EigenValue) можно рассматривать как важную компоненту в построении численно-аналитических подходов, которые альтернативны простым пошаговым схемам интегрирования типа Рунге-Кутта в задачах большого размера. Можно получить определенные выгоды, если матрицы линейных преобразований предварительно привести к простой форме. Такой подход широко используется в динамике (модальный анализ). В данной работе предложена схема алгоритма пошагового численного анализа структуры матрицы $K$ в проблеме $(K, E) \rightarrow(J, E)$ и схема построения жорданового базиса для общего случая корней характеристического полинома (для действительных и комплексных корней, простых и кратных). В качестве стартовой формы принята стандартная проблема собственных значений с матрицей К предварительно приведенной к форме Шура (матрице блочно-треугольной формы) . Схема сопровождается решением модельных примеров.

Ключевые слова: проблема собственных значений, каноническая форма, жордановый базис, численный алгоритм.

\section{V.M. GRISCHENKO}

\section{THE SCHEME OF THE ALGORITHM FOR THE STEP-BY-STEP REDUCTION OF TWO MATRICES IN THE FORM OF SCHUR TO A SIMPLE FORM}

Of great importance for modern technology are the issues of the dynamic behavior of machines and structures. Given the trends of today such as new information technologies, the transformation of design processes; creation of CAD systems (automation systems for design work), issues of improving methods for solving dynamics problems are of particular importance. Numerical modeling has become an integral part of the study of the most complex processes for the most complex physical models, and the Finite Element Method has become the main numerical method for their study. These trends will inevitably be accompanied by a significant increase in the number of parameters for determining the state of the object. In particular, in the dynamics of machines, a significant number of degrees of freedom. As a result, the appearance of the problem of a multiple increase in the size of the task.

The solution of the eigenvalue problem can be considered as an important component in the construction of numericalanalytical approaches that are alternative to simple step-by-step integration schemes of the Runge-Kutta type in large-scale problems. Certain benefits can be obtained if the linear transformation matrices are first reduced to a simple form. This approach is widely used in dynamics (modal analysis). In this paper, we propose a scheme for a step-by-step numerical analysis of the structure of the matrix 
$K$ in a problem $(K, E) \rightarrow(J, E)$ and a scheme for constructing a Jordan basis for the general case of roots of a characteristic polynomial (for real and complex roots, simple and multiple). As the starting form, the standard eigenvalue problem with the matrix K previously reduced to the Schur form (block-triangular shape matrix) is adopted. The scheme is accompanied by the solution of test cases.

Keywords: eigenvalue problem, canonical form, Jordan basis, numerical algorithm.

Вступ. Рішення багатьох прикладних задач сучасної техніки невпинно ускладнюються одночасно $з$ запитами на створення більш складних конструкцій та об'єктів. Значні навантаження, складні умови експлуатації, різноманітність структурних схем енергетичних машин, парових, газових турбін, трансмісійних машин та інших приводять до високих рівнів напруженості у всіх ланках та вузлах. Робота таких складних конструкцій супроводжується сумісною деформацією частин установок як єдиних динамічних систем. Особливо небезпечним є динамічний (циклічний) характер процесів в широкому діапазоні частот, коли стає актуальною проблема усунення вібрацій резонансного типу з робочих діапазонів роботи. Для рішення зазначених задач використовуються різні моделі, методи, програмне забезпечення. Але, безсумнівно, головною тенденцією буде залишатись перехід до моделювання все більш реальних умов експлуатації, моделювання все більш складних за формою механізмів, об'єктів та процесів. Зазначені тенденції невідворотно будуть супроводжуватись значним ростом кількості параметрів визначення стану об'єктів. Зокрема, в динаміці машин, теорії коливань моделювання потребуватимуть введення значної кількості степенів вільності. Тільки такий підхід дозволяє детально кількісно та якісно визначати поведінку конструкцій та явищ, та, як наслідок, появу проблеми багатократного збільшення розмірів задачі.

В практичних методах дослідження процесів в прикладних технічних об'єктах мають справу з системами складних нелінійних диференціальних рівнянь. Але в подальшому в процесі аналізу досить часто акценти зміщуються до розгляду систем еквівалентних лінійних рівнянь. Це пов'язано з тим, що теоретичні положення рішення лінійних диференціальних рівнянь добре розроблені та викладені як в науковій літературі так і в численних підручниках по аналізу [10, 12]. Разом $з$ тим, не все так ясно з чисельною реалізацією таких рівнянь. Аспекти інженерного рішення «до числа» в літературних джерелах для різних варіантів наводяться детально, переважно, для рівнянь невеликого розміру, і або не можуть бути використаними, або не $\epsilon$ ефективними в загальному випадку.

Разом $з$ тим, одержати адекватне рішення задач практичних розмірів можливо, в більшості випадків, чисельними методами. Чисельні підходи в наш час перетворились в самостійний розділ прикладної математики, в провідний напрямок моделювання поведінки систем, а в багатьох випадках і єдиний. I цей напрямок в практичних розрахунках продовжує активно розвиватись у зв'язку з широким застосуванням комп'ютерних технологій.

Одним $з$ найбільш ефективних підходів моделювання складних багато функціональних систем в інженерних дослідженнях став метод скінченних елементів (MCE) - Finite Element Method (FEM) [5, 9]. Формалі- зація задачі в формі МСЕ, при якій проводиться дискретизація поля невідомих 3 переходом до узагальнених координат має багато переваг. Одна 3 них - це матрична трактовка розрахункових співвідношень. Значне коло прикладних задач також знаходить компактну форму вираження саме в матричній інтерпретації. Саме тому чисельні методи матричної алгебри відіграють визначну роль в обчислювальній математиці. А такі характеристики чисельних процедур як оптимальна кількість операцій та потрібна оперативна пам'ять, стійкість алгоритму (мінімізація помилок ) в поєднанні з розробкою ефективної схеми алгоритму стають тими стратегічними факторами, які можуть ефективно протистояти проблемі багатократного збільшення розмірів задачі. Становиться очевидним, що для успішного рішення великих систем чисельними методами на ЕОМ потрібні алгоритми спеціально розроблені для конкретного типу задач.

Важливого значення в машинобудуванні мають питання динамічної поведінки машинних агрегатів, питання їх віброзахисту та інші. Традиційні підходи чисельного інтегрування матричних систем диференціальних рівнянь динаміки більш-менш значимих розмірів покроковими методами типу Рунге-Кутта є простим універсальним засобом аналізу, але потребують великих затрат часу й ресурсів, не враховують в повному обсязі специфіку рішення та $є$ умовно стійкими. Альтернативою можуть стати різні варіанти чисельно-аналітичних підходів, які включають попередне приведення систем рівнянь до більш простої структури ( однієї з канонічних ). Ця частина потребує розробки ефективних схем. Канонічна форма рівнянь надає значні переваги в загальній схемі обчислень, такі як:

- використання аналітичної складової в процесі обчислень підвищує точність та стійкість алгоритму, скорочує час;

- чисельно-аналітичний підхід дає можливість більш детального аналізу структури рішення, зменшує труднощі обчислювального характеру та інші.

В теорії коливань, матричній алгебрі до таких проблемних питань відноситься побудова алгоритму визначення власних значень та канонічної форми рівнянь.

1. Постановка задачі. Домінуючим засобом аналізу поведінки об'єктів сучасної техніки є чисельні методи. Для подолання обчислювальних труднощів вигідною $є$ матрична трактовка основних співвідношень проблеми і щонайбільш важливим - це розробка простих обчислювальних схем ефективних для конкретних задач. Рішення проблеми власних значеньвласних векторів (форм коливань) набуває значення в дослідженнях задач динамічної поведінки машинних агрегатів і в узагальненій формі має такий вигляд:

$$
K x=\lambda M x,
$$

де $(K, M)$ - задані квадратні матриці порядку $n$;

$(\lambda, x)$ - власні значення та власні вектори пробле- 
ми. Рішення EigenValue, зокрема, може розглядатись як важлива компонента в побудові чисельноаналітичних підходів, які альтернативні простим покроковим схемам інтегрування типу Рунге-Кутта в задачах великого розміру. Можна одержати певні переваги, якщо матриці лінійних перетворень попередньо привести до простих форм. Ці приведення можна виконати чисельно за певною схемою. Такий підхід не $\epsilon$ новим і широко застосовується в динаміці (модальний аналіз), коли, наприклад, в базисному підпросторі матриця оператора приводиться до діагонального виду:

$$
(K, M) \rightarrow(\Lambda, E)
$$

В подібних схемах побудови практичних алгоритмів важливим фактором є здатність цих алгоритмів функціонувати в широкому діапазоні значень коефіцієнтів та видів матриць, тобто бути універсальними. Але відомо, що при рішенні задач наукового та прикладного спрямування можуть виникати ситуації, що потребують окремого розгляду. Відомо, що не для кожного лінійного оператора існує базис, в якому його матриця має діагональну форму (2). Проте кожна дійсна матриця подібна блочно - діагональній з діагональними блоками 1-го та 2-го порядків (квазидіагональній) (як на рис. 1). Блокам 2-го порядку відповідають пари комплексно-спряжених власних значень.

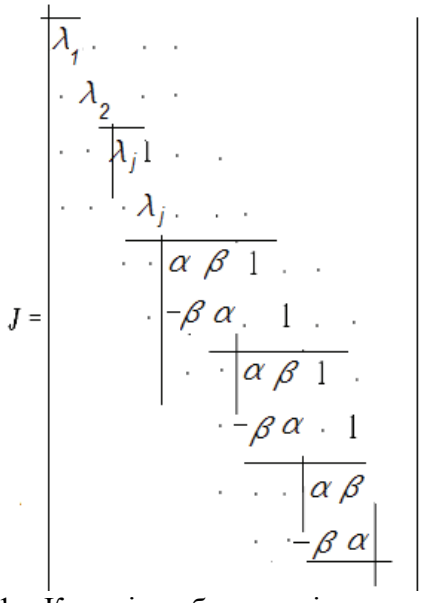

Рисунок 1 - Канонічна блочно-діагональна форма матриці лінійного оператора (форма Жордана)

Теорема Жордана для матриці кожного лінійного оператора вказує одну із таких простих структур (канонічну форму $J)[1,7,10,12]$. Вона відрізняється від діагональної форми тим, що на деяких місцях в рядку, що розташований вище від головної діагоналі і паралельній їй знаходяться ненульові позиції (частіше одиниці). Діагональна матриця - це частинний випадок жорданової матриці для випадку простих дійсних коренів та лінійних елементарних дільників. Поява в структурі матриці жорданових кліток обумовлена появою кратних коренів характеристичного поліному, та кратних значень елементарних дільників.

Теоретичні основи побудови жорданового базису та лінійного перетворення для різних ситуацій в структурі матриць проблеми $(K, M) \rightarrow 0)$ досить повно викладені в спеціальних розділах матричної алгебри [1, $7,12]$. Приводиться також послідовність дій для побудови такого базису (не зачіпаючи чисельний аспект цієї проблеми). Яку аж ніяк не можна вважати ефективним алгоритмом.

Ціль даної роботи запропонувати схему алгоритму чисельного аналізу структури матриці К в проблемі

$$
(K, E) \rightarrow(J, E)
$$

та схему побудови жорданового базису для загального випадку структури коренів характеристичного поліному (випадки дійсних та комплексних коренів, простих та кратних, з лінійними та нелінійними елементарними дільниками). В якості стартової форми прийнята стандартна проблема власних значень з матрицею К попередньо приведеною до форми Шура (матрицею блочно-трикутної форми) (3).

2. Основні положення алгоритму. Спочатку розглянемо основні кроки та особливості існуючого теоретичного підходу в побудові жорданового базису, виділяючи при цьому проблемні для чисельної реалізації позиції :

• розпочати потрібно з пошуку коренів характеристичного поліному та визначенні їх кратності ;

- наступна послідовність дій направлена на побудову корневого підпростору і виконується для кожного кореня $\lambda^{*}$ :

- 3 цією метою будується вироджена матриця оператора зі зсувом $\left(K-\lambda^{*} E\right)$, та визначається iї власний вектор $u^{0}$;

- як тільки знайдено $u^{0}$, то для випадку кратних коренів 3 нелінійними елементарними дільниками, $з$ нього розпочинається ланцюг рівнянь для одержання приєднаних векторів $u^{1}, u^{2}, .$. і т.д.:

$$
\left(K-\lambda^{*} E\right) u^{i}=u^{i-1} \text {. }
$$

Проводиться аналіз іiі рангу. Якщо $\operatorname{Rg}\left(K-\lambda^{*} E\right)>n-m$, де $m$ кратність кореня, то $\left(K-\lambda^{*} E\right)$ зводиться в степінь $2,3, \ldots k$ і т. д. поки не буде знайдено таке $k$ для якого $\operatorname{Rg}\left(K-\lambda^{*} E\right)^{k}=n-m$.

Знайдена множина приєднаних векторів доповнює підпростір власних до базису кореневого підпростору цього кореня.

Приведена послідовність кроків досить складна, більш теоретична, відіграє свою роль в процесі доведення основних положень теореми Жордана, але в такій формі непридатна для створення ефективного алгоритму:

- потребує невиправданих затрат пам'яті та часу на роботу з матрицями:

- аналіз величин $\operatorname{Rg}\left(K-\lambda^{*} E\right)$ виправданий лише для матриць невеликого розміру та інші.

Тепер приведемо ключові елементи запропонованої схеми. Поставлена тут задача - це розробка алгоритму побудови жорданового базису в стандартній проблемі власних значень з матрицею К в формі Шура (рис. 2).

Прийнята як стартова така форма матриці дозволяє просто визначати всі корені: дійсні, які стоять на діагоналі та комплексно-спряжені, які визначаються клітками 2х2, та встановлювати їх кратність. Перетворення подібності здійснюється за допомогою модальної матриці U за схемою:

$$
U^{-1}(K-\lambda E) U \rightarrow(J-\lambda E) .
$$

Вісник Національного технічного університету «ХПI». Серія: Динаміка і міиність машин. № 2.2019 
$(K-\lambda E)=\left(\begin{array}{lllllllll}k & k & k & k & k & k & k & k & k \\ k & k & k & k & k & k & k & k & k \\ \cdot \cdot & \cdot & k & k & k & k & k & k & k \\ \cdot & \cdot & \cdot & k & k & k & k & k & k \\ \cdot & \cdot & \cdot & k & k & k & k & k & k \\ \cdot & \cdot & \cdot & \cdot & \cdot & k & k & k & k \\ \cdot & \cdot & \cdot & \cdot & \cdot & \cdot & k & k & k \\ \cdot & \cdot & \cdot & \cdot & \cdot & \cdot & k & k & k \\ \cdot & \cdot & \cdot & \cdot & \cdot & \cdot & \cdot & \cdot & k\end{array} \mid-\lambda E\right)$

Рисунок 2 - Стандартна проблема власних значень з матрицею К в формі Шура

Зважаючи на структуру матриці $K$, перетворення $U$ також приймається у відповідній їй квазитрикутній формі. Для зберігання коефіцієнтів матриці оператора після подібних перетворень у тому ж самому масиві, $\mathrm{i}$ для зручності поточного аналізу коренів характеристичного поліному розглядається покроковий процес реалізації подібного перетворення. 3 цією метою структура матриці $U$ представляється послідовним ланцюгом стовбців відповідно до порядку коренів: дійсних або пари комплексно спряжених. А надалі ця послідовність в $U$ реалізується співмножниками $N_{s}$. Приклад структурної організації $U$ для $n=5$ приведений нижче:

$$
U=\left[\begin{array}{ccccc}
1 & u_{12} & u_{13} & u_{14} & u_{15} \\
\cdot & 1 & u_{23} & u_{24} & u_{25} \\
\cdot & \cdot & u_{33} & u_{34} & u_{35} \\
\cdot & \cdot & u_{43} & u_{44} & u_{45} \\
\cdot & \cdot & \cdot & \cdot & 1
\end{array}\right]=N_{5} * N_{43} * N_{2}
$$

де $N_{s}$ - праве неунітарне стійке елементарне перетворення ;

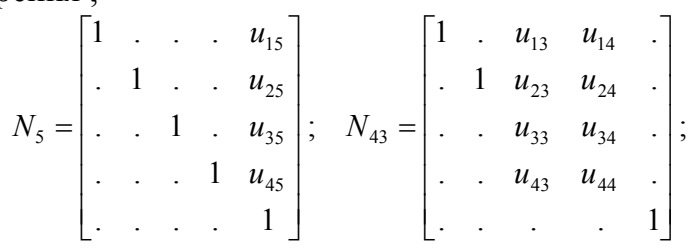

$$
\begin{aligned}
& N_{2}=\left[\begin{array}{ccccc}
1 & u_{12} & \cdot & \cdot & \cdot \\
\cdot & 1 & \cdot & \cdot & \cdot \\
\cdot & \cdot & 1 & \cdot & \cdot \\
\cdot & \cdot & \cdot & 1 & \cdot \\
\cdot & \cdot & \cdot & \cdot & 1
\end{array}\right]
\end{aligned}
$$

і т. д.

Кожен зі співмножників $N_{s}$ - це елементарна матриця, яка по перше - виконує перетворення тільки тих стовбців К, які пов'язані зі своїм коренем; по друге - для цього перетворення просто знайти зворотнє, наприклад

$$
N_{s}^{-1}=\left[\begin{array}{ccccc}
1 & \cdot & -u_{1 s} & \cdot & \cdot \\
\cdot & 1 & -u_{2 s} & \cdot & \cdot \\
\cdot & \cdot & 1 & \cdot & \cdot \\
\cdot & \cdot & \cdot & 1 & \cdot \\
\cdot & \cdot & \cdot & \cdot & 1
\end{array}\right] \cdot
$$

По третє - чисельні значення окремого перетворення $N_{j}$ можна визначати, наприклад, послідовно 3 вироджених рівнянь зі зсувами

$$
\left(K-\lambda^{*} E\right) \mathrm{u}^{\mathrm{i}} \rightarrow 0 .
$$

Згідно $з$ цим порядком знайдений вектор $u^{j}$ може бути як власним для задачі (6) так і приєднаним (4). Є лише одна відмінність, яка відрізняє їх: для простих коренів система рівнянь сумісна і можна знайти такі значення $u^{j}$ (власного вектора), що права частина буде точно дорівнювати 0. Для випадку кратних коренів на діагоналі з'являються додаткові 0, система рівнянь може бути несумісною, тобто знайти такі $u^{j}$, щоб елементи правої частини (6) всі дорівнювала 0 неможливо). В таких випадках потрібно обмежитись таким набором $u^{j}$ (приєднаний вектор), щоб права частина (6) «майже» дорівнювала 0, нехтуючи тими умовами, які несумісні.

Структура матриці $U$ така, що для випадку дійсного кореня елементарні матриці, наприклад, $N_{5}, N_{2}$ містять один стовбець $u_{i j}$, а для випадку комплексноспряжених таких стовбців два (5). Алгоритм їх визначення складніший.

Таким чином, в довільному випадку, аналіз структури матриці лінійного оператора виконується чисельно. Жордановий базис, який складається 3 векторів матриці U, визначається неоднозначно, чисельно, шляхом аналізу рішень рівняння $(4,5)$.

Визначати спочатку власний вектор, потім будувати ланцюги рівнянь типу (4) для приєднаних, аналізувати $\operatorname{Rg}\left(K-\lambda^{*} E\right)$ не потрібно. Розглянемо дію схеми на модельних прикладах.

3.Результати чисельних розрахунків Для чисельних розрахунків вибрано два модельних приклади: один 3 дійсними кратними коренями, інший 3 комплексними.

Приклад 1. (7x7) стандартна проблема з кратними дійсними коренями.

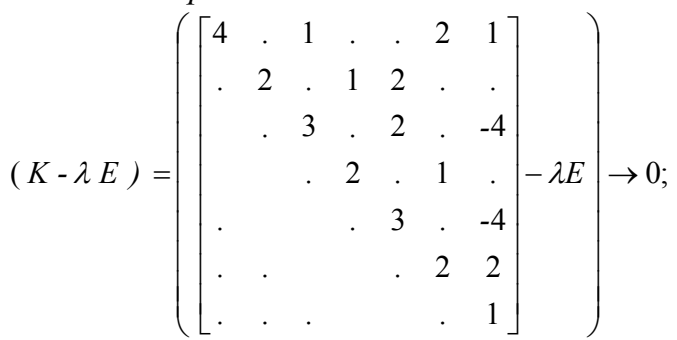

Має такі дійсні власні значення:

\begin{tabular}{|c|c|c|c|c|c|c|c|}
\hline № & 1 & 2 & 3 & 4 & 5 & 6 & 7 \\
\hline$\lambda_{\mathrm{s}}$ & 4 & 2 & 3 & 2 & 3 & 2 & 1 \\
\hline
\end{tabular}

Кратними $є$ корені $\lambda_{2,4,6}=2$ і $\lambda_{3,5}=3$.

Згідно 3 наведеним вище структура перетворення подібності визначається структурою матриці $U(K)$, представляється послідовним добутком матриць $N_{s}$, пов'язаних зі своїми стовбцями та реалізується рішеннями матричних рівнянь зі зсувами. В нашому прикладі, де тільки дійсні корені, всі $N_{s}$ містять по одному стовбцю.

Розглянемо покроково в установленому вище порядку (5) обчислення складових $U-$ неунітарних перетворень $N_{s}$.

1) $\lambda_{7}=\mathbf{1}$;

Матриця $K$ зі зсувом $\lambda_{7}$ та елементарна $N_{7}$ будуть мати такий вид:

$$
\left(K-\lambda_{7} E\right) N_{7}=
$$




$$
=\left[\begin{array}{ccccccc}
3 & . & 1 & . & . & 2 & 1 \\
. & 1 & . & 1 & 2 & . & . \\
& . & 2 & . & 2 & . & -4 \\
& & \cdot & 1 & . & 1 & . \\
. & & & . & 2 & . & -4 \\
. & . & & & . & 1 & 2 \\
. & . & . & & & . & .
\end{array}\right]\left[\begin{array}{ccccccc}
1 & . & . & . & . & . & 1 \\
\cdot & 1 & . & & & . & -6 \\
. & 1 & . & & . & . \\
& . & 1 & . & & 2 \\
. & & & . & 1 & . & 2 \\
\cdot & . & & & . & 1 & -2 \\
. & . & . & & & . & 1
\end{array}\right] \rightarrow 0 .
$$

На діагоналі стоїть один 0 . В сьомому стовбці $N_{7}$ побудовано власний вектор $u_{7}$ для простого кореня $\lambda_{7}$. Подібне перетворення $K$ з використанням $u_{7}$ дає:

$$
K_{6}=\left(N_{7}\right)^{-1}\left(K-\lambda_{7} E\right) N_{7} \rightarrow\left[\begin{array}{ccccccc}
3 & . & 1 & . & . & 2 & \bullet \\
. & 1 & . & 1 & 2 & . & \bullet \\
& . & 2 & . & 2 & . & \bullet \\
& & . & 1 & . & 1 & \bullet \\
. & & & . & 2 & . & \bullet \\
. & . & & & . & 1 & \bullet \\
. & . & . & & & . & \bullet
\end{array}\right]
$$

Тепер 7-ий стовбець цієї матриці нульовий.

2) $\lambda_{7}=2$;

Корінь кратний. В матриці $\left(N_{7}\right)^{-1}\left(K-\lambda_{6} E\right) N_{7}$ зі зсувом $\lambda_{6}$ на діагоналі стоять три нуля, а в 6-му стовбці елементарної $N_{6}$ побудовано приєднаний вектор $u_{6}$ кореня $\lambda_{6}:\left[\left(N_{7}\right)^{-1}\left(K-\lambda_{6} E\right) N_{7}\right] N_{6} \rightarrow$

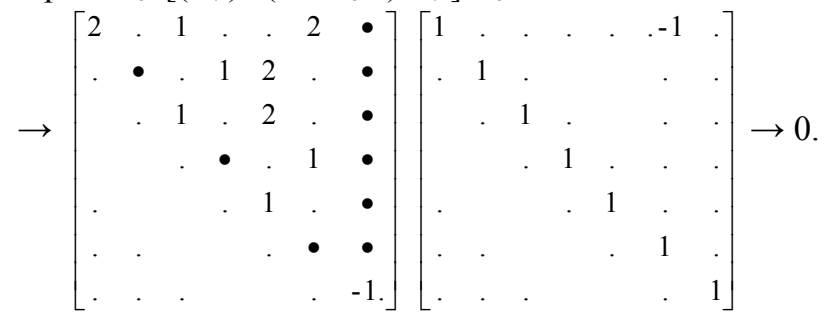

Якщо завершити виконання перетворення подібності матриці $K$ з використанням тепер вже двох векторів $K_{7}$ та $K_{6}$, то одержимо:

$$
\begin{gathered}
K_{5}=\left(N_{6}\right)^{-1}\left(N_{7}\right)^{-1}\left(K-\lambda_{6} E\right) N_{7} N_{6} \rightarrow \\
\rightarrow\left[\begin{array}{ccccccc}
2 & \cdot & 1 & . & . & \bullet & \bullet \\
\cdot & \bullet & . & 1 & 2 & \bullet & \bullet \\
& \cdot & 1 & . & 2 & \bullet & \bullet \\
& & \cdot & \bullet & \cdot & 1 & \bullet \\
\cdot & & & \cdot & 1 & \bullet & \bullet \\
\cdot & . & & & \cdot & \bullet & \bullet \\
\cdot & . & . & & & \cdot & -1 .
\end{array}\right] .
\end{gathered}
$$

Видно, що в випадку використання для $U$ приєднаних векторів в шостому стовбці після цього залишаються ненульові позиції, тобто матриця після перетворення не буде набувати діагональної форми.

3) $\lambda_{5}=3$;

Теж кратний. В матриці $\left(N_{6}\right)^{-1}\left(N_{7}\right)^{-1}\left(K-\lambda_{5} E\right) N_{7} N_{6}$ зі зсувом $\lambda_{5}$ на діагоналі стоять два нуля, а в 5-му стовбці елементарної $N_{5}$ побудовано приєднаний вектор $u_{5}$ кореня $\lambda_{5}:\left[\left(N_{6}\right)^{-1}\left(N_{7}\right)^{-1}\left(K-\lambda_{5} E\right) N_{7} \mathrm{~N}_{6}\right] \mathrm{N}_{5} \rightarrow$

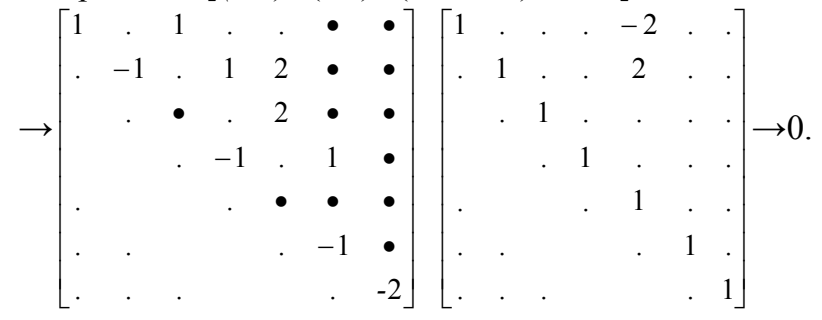

Завершення перетворення подібності $K$ з використанням векторів $u_{7}, u_{6}$ та $u_{5}$, дає:

$$
\begin{aligned}
K_{4}= & \left.\left(N_{5}\right)^{-1} N_{6}\right)^{-1}\left(N_{7}\right)^{-1}\left(K-\lambda_{5} E\right) N_{7} N_{6} N_{5} \rightarrow \\
& \rightarrow\left[\begin{array}{ccccccc}
1 & \cdot & 1 & \cdot & -2 & \bullet & \bullet \\
\cdot & -1 & \cdot & 1 & \bullet & \bullet & \bullet \\
& \cdot & \bullet & . & 2 & \bullet & \bullet \\
& & \cdot & -1 & \cdot & 1 & \bullet \\
\cdot & & & \cdot & \bullet & \bullet & \bullet \\
\cdot & \cdot & & & \cdot & -1 & \bullet \\
\cdot & \cdot & . & & & \cdot & -2
\end{array}\right] .
\end{aligned}
$$

Видно, що при використанні приєднаних векторів, поза діагоналлю знову з'являються ненульові позиції і т.д.

По закінченню ланцюга покрокових обчислень буде сформована матриця 3 векторів базису даного лінійного оператора. В наведеному прикладі вона має такий вигляд:

$$
U=\left[\begin{array}{ccccccc}
1 & \cdot & -1 & \cdot & \cdot-2 & -1 & 1 \\
\cdot & 1 & \cdot & \cdot & 2 & \cdot & -6 \\
& \cdot & 1 & \cdot & \cdot & \cdot & \cdot \\
& & \cdot & 1 & \cdot & \cdot & 2 \\
\cdot & & & \cdot & 1 & \cdot & 2 \\
\cdot & \cdot & & & \cdot & 1 & -2 \\
\cdot & . & . & & & . & 1
\end{array}\right] .
$$

Матриця $K$ в цьому базисі прийме просту форму:

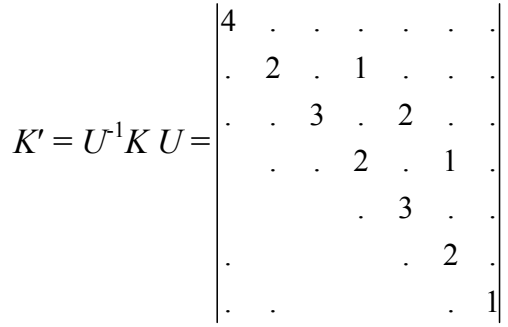

Або після перестановки рядків та стовбців матриця набуде вигляду, близького до канонічного:

$$
K^{\prime \prime}=\left|\begin{array}{ccccccc}
4 & \cdot & \cdot & \cdot & \cdot & \cdot & \cdot \\
\cdot & 2 & 1 & \cdot & \cdot & \cdot & \cdot \\
\cdot & \cdot & 2 & 1 & \cdot & \cdot & \cdot \\
\cdot & \cdot & 2 & \cdot & \cdot & \cdot \\
& & & \cdot & 3 & 2 & . \\
\cdot & & & & \cdot & 3 & \cdot \\
. & . & & & & \cdot & 1
\end{array}\right| .
$$

Приклад 2. (6х6) стандартна проблема з кратними комплексними коренями.

$$
(K-\lambda-)=\left(\left[\begin{array}{cccccc}
1 & \cdot & \cdot & 2 & \cdot & \cdot \\
\cdot & 1 & 1 & \cdot & \cdot & \cdot \\
\cdot & -4 & 1 & \cdot & 1 & \cdot \\
\cdot & \cdot & \cdot & 3 & \cdot & 1 \\
\cdot & \cdot & \cdot & \cdot & \bullet & -5 \\
\cdot & \cdot & \cdot & \cdot & 1 & 2
\end{array}\right]-\lambda E\right) \rightarrow 0 .
$$

Система має наступні дійсні та комплексноспряжені власні значення :

\begin{tabular}{|c|c|c|c|c|}
\hline № & 1 & 2,3 & 4 & 5,6 \\
\hline$\lambda_{\mathrm{s}}$ & 1 & $1 \pm 2 \mathrm{i}$ & 3 & $1 \pm 2 \mathrm{i}$ \\
\hline
\end{tabular}

Кратними є корені $\lambda_{2,5}=1+2 \mathrm{i}, \quad$ i $\lambda_{3,6}=1-2 \mathrm{i}$. 
Принципові положення чисельного алгоритму залишаються незмінними: структура модальної матриці відповідає структурі $K$. Проте процес визначення модальних стовбців дещо ускладнюється..

Приведемо тут структурну композицію модальної матриці в чисельному виконанні згідно наведеної схеми.

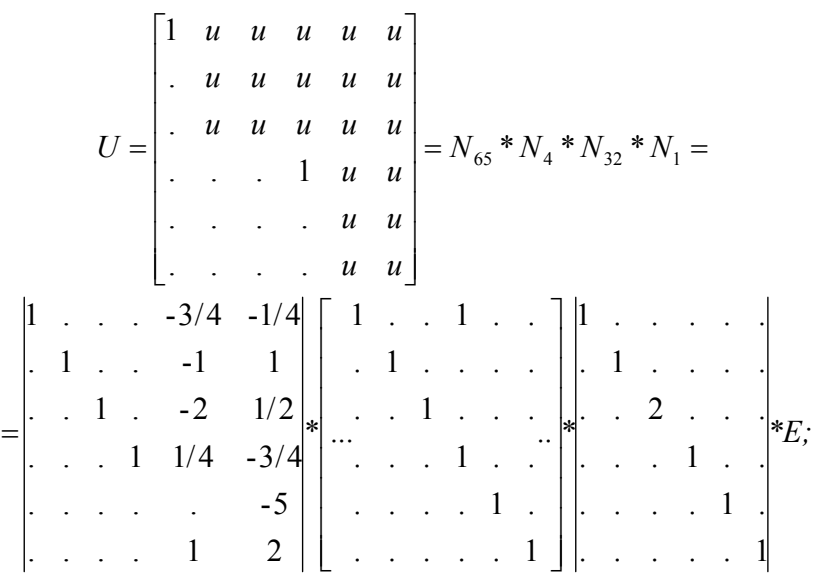

Заключна еквівалентна форма простого виду для рівняння з комплексними коренями така:

$$
K^{\prime}=U^{-1} K U=\left|\begin{array}{cccccc}
1 & . & . & . & . & \cdot \\
\cdot & 1 & 2 & . & . & 5 / 2 \\
\cdot & -2 & 1 & . & . & \cdot \\
\cdot & \cdot & \cdot & 3 & . & \cdot \\
\cdot & \cdot & . & . & 1 & 2 \\
\cdot & . & . & . & -2 & 1
\end{array}\right| .
$$

Одержані рівняння лінійного оператора в базисі Жордана мають значні переваги в подальшому чисельно-аналітичному дослідженні задач, так як рішення ix може розпадатись на серію задач меншого розміру.

Зауваження .В літературі по матричній алгебрі, в розділах, які пов'язані з проблемою побудови жорданового базису приводяться деякі не зовсім характерні, на наш погляд , приклади .

Наприклад : $K=\left|\begin{array}{cccc}3 & -1 & \cdot & -1 \\ 1 & 1 & . & -1 \\ \cdot & . & 2 & -1 \\ . & . & 1 & \end{array}\right|$.

Так, це приклад матриці, яка має кратні, але дійсні корені. Тому всі такі матриці можуть попередньо 3 допомогою еквівалентного перетворення бути приведені до чистої трикутної форми.

Висновки. По результатам проведених досліджень можна зробити наступні висновки:

Запропонована схема алгоритму побудови жорданового базису для загального випадку коренів матриці лінійного оператора та для випадку , коли матриця проблеми попередньо приведена до форми Шура.

В основі схеми лежить принцип формування структури модальної матриці $U$ у відповідності зі структурою самої матриці оператора $K$, та наступним представленням її у вигляді ланцюга елементарних матриць..

Відзначимо, що потрібна певна практика у напрацюванні зручних прийомів рішення задач та використанні цієї схеми.

\section{Список літератури:}

1. Булгаков Б.В. Колебания. Москва: ГИТТЛ, 1954, 892 с.

2. Мальцев А.И. Основы линейной алгебры. Москва: Гостехиздат, 1956.

3. Бабаков И.М. Теория колебаний. Москва: Наука, $1968,560 \mathrm{c}$

4. Гантмахер Ф.Р.Теория матриц. Москва: Гостехиздат, 1967. $575 \mathrm{c}$.

5. Бате К., Вилсон Е. Численные методы анализа и метод конечных элементов. Москва: Стройиздат, 1982. 448 с.

6. Воеводин В.B. Вычислительные основы линейной алгебры. Москва: Наука, 1977. 304 с.

7. Воеводин В.В., Кузнецов Ю.А. Матрицы и вычисления. Москва: Наука, 1984. 320 с $280 \mathrm{c}$.

8.. Ланкастер П. Теория матриц. Москва: Наука, 1978.

9. Постнов В.А, Хархурим И.Я. Метод конечных элементов в расчетах судовых конструкций. Ленинград: Судостроение, 1974.

10. Якубович В.А., Старжинский В.М. Линейные дифференциальные уравнения с периодическими коэффициентами и их приложения. Москва: Наука, 1972, 720 с.

11. Форсайт Дж, Малькольм М.,Моулер К. Машинные методы математических вычислений. Москва: Мир, 1980. $280 \mathrm{c}$.

12. Беклемишев Д.В. Дополнительные главы линейной алгебры. Москва: Наука, 1983. 336 с.

Bibliography (transliterated)

1. Bulgakov B.V. Kolebaniya. Moscow: GITTL, 1954, 892 p.

2. Mal'cev A.I. Osnovy linejnoj algebry. Moscow: Gostehizdat, 1956. $560 \mathrm{p}$.

3. Babakov I.M. Teoriya kolebanij. Moscow: Nauka, 1968 ,

4. Gantmaher F.R.Teoriya matric. Moscow: Gostehizdat, 1967. $575 \mathrm{p}$

5. Bate K., Vilson E. Chislennye metody analiza i metod konechnyh elementov. Moscow: Strojizdat, 1982. 448 p.

6. Voevodin V.V. Vychislitel'nye osnovy linejnoj algebry. Moscow: Nauka, 1977. 304 p.

7. Voevodin V.V., Kuznecov Yu.A. Matricy i vychisleniya. Moscow: Nauka, 1984. 320 p.

8. Lankaster P. Teoriya matric. Moscow: Nauka, 1978. $280 \mathrm{p}$.

9. Postnov V.A, Harhurim I.Ya. Metod konechnyh elementov v raschetah sudovyh konstrukcij. Leningrad: Sudostroenie, 1974.

10. Yakubovich V.A., Starzhinskij V.M. Linejnye differencial'nye uravneniya s periodicheskimi koefficientami i ih prilozheniya. Moscow: Nauka, 1972, $720 \mathrm{p}$.

11. Forsajt Dzh, Mal'kol'm M.,Mouler K. Mashinnye metody matematicheskih vychislenij. Moscow: Mir, 1980. 280 p.

12. Beklemishev D.V. Dopolnitel'nye glavy linejnoj algebry. Moscow: Nauka, 1983. 336 p.

Надійшла (received) 08.10.2019

\section{Відомості про авторів / Сведения об авторах / About the Authors}

Грищенко Володимир Миколайович (Грищенко Владимир Николаевич, Grischenko Volodymir Mykolayovich) - кандидат технічних наук, доцент кафедри динаміки та міцності машин, НТУ «ХПІ», тел.: (057) 707-6879; e-mail: grivn_dmm@ukr.net. 